\title{
On-pump total arterial revascularization
}

\author{
Sajjad Raza, Salil V. Deo, Joseph F. Sabik III \\ Department of Surgery, University Hospitals Cleveland Medical Center, Cleveland, OH, USA \\ Correspondence to: Joseph F. Sabik III, MD. Chair, Department of Surgery; Surgeon-in-Chief and Vice President for Surgical Operations, University \\ Hospitals Cleveland Medical Center Professor of Surgery, CWRU School of Medicine, 11100 Euclid Avenue, Lakeside 7, Cleveland, Ohio 44106- \\ 7060, USA. Email: Joseph.Sabik@UHHospitals.org.
}

Submitted Mar 02, 2018. Accepted for publication May 28, 2018.

doi: 10.21037/acs.2018.06.06

View this article at: http://dx.doi.org/10.21037/acs.2018.06.06

\section{Clinical vignette}

A forty-year-old man presented with history of chest pain and myocardial infarction. He was overweight, had hyperlipidemia and smoked cigarettes in the past. His family history included early onset coronary artery disease (CAD). Echocardiography showed normal function and normal valves. Angiogram showed extensive $\mathrm{CAD}$ with stenosis in proximal left anterior descending (LAD) coronary artery, subtotal occlusion of mid LAD, and significant stenosis in diagonal, circumflex, distal right coronary artery (RCA) and posterior descending artery.

\section{Surgical techniques}

\section{Preparation}

The patient was placed supine, and after induction of general anesthesia, was prepped and draped in the usual sterile fashion.

\section{Exposition}

A median sternotomy incision was made and the sternum divided using a sternal saw.

\section{Operation}

Given the age and coronary anatomy of the patient, we decided to do total arterial revascularization (see video). We planned to use in situ left internal thoracic artery (ITA) to graft his diagonal and LAD in a sequential fashion, right ITA as a composite Y-graft from the left ITA to graft the two branches of the circumflex sequentially, radial artery to graft the diagonal, and gastroepiploic artery (GEA) to graft the RCA. We planned to do the procedure on-pump-our default option for most patients undergoing coronary artery bypass grafting (CABG).

Both ITAs were harvested in skeletonized fashion. We highly recommend harvesting ITAs in skeletonized fashion as it has shown to be associated with decreased risk of deep sternal wound infections compared to pedicled ITA harvest. During harvesting, we dissected out the branches very carefully and left as much tissue as we could on the chest wall so as not to devascularize it. The radial artery was harvested endoscopically. For harvesting the GEA, we did not extend the midline incision because in patients undergoing bilateral ITA grafting, sternal healing is already compromised. Instead, we made a little incision just below the diaphragm, brought the stomach anterior to the liver and dissected out GEA very carefully from the areolar tissue. We routinely clip the small gastric arteries from the GEA and then divide them. The GEA is a relatively thin walled vessel and hence, needs to be handled delicately. Ensuring accurate clipping of branches avoids the development of sub-adventitial hematoma, which may compromise flow and patency.

Once the conduits were harvested, the patient was placed on cardiopulmonary bypass. The ascending aorta was crossclamped and the heart was arrested with first antegrade and then retrograde cold blood cardioplegia.

We used the right ITA as a free graft off the in situ left ITA in Y-configuration and grafted two branches of the circumflex sequentially, first by side-to-side anastomosis to one branch of circumflex and then by end-to-side anastomosis to the other branch. We constructed the sideto-side anastomosis in a parallel fashion using 7-0 or 8-0 
prolene sutures. We believe constructing this anastomosis in a parallel $v s$. diamond fashion reduces the chances of getting the seagull effect or obstruction of anastomosis that can occur particularly when the ITA is small. The distal end-to-side anastomosis of this sequential graft was then constructed to the very large lateral circumflex using 7-0 or 8-0 prolene sutures. Left ITA was used to graft the diagonal and LAD in a sequential fashion, first by side-to-side parallel anastomosis to the second diagonal and then endto-side anastomosis to the distal LAD. The radial artery was used to graft the higher diagonal as a free graft off the aorta. We brought GEA in the abdomen anterior to the liver and then through a cruciate incision in the diaphragm and anastomosed it to the PDA using 8-0 prolene sutures (see video).

\section{Completion}

After constructing the anastomoses, it is worthwhile to take a look at the grafts and their lie to make sure there is no kinking. An arterial graft fixed in two places can twist and kink. Therefore, we routinely fix grafts in different places with 6-0 sutures. This additional fixation can prevent the grafts from kinking or twisting. Also, if the graft is too long, forming it into an " $\mathrm{S}$ " using 6-0 prolene sutures can avoid kinking or twisting issues.

Once grafting was completed, a "hot shot" dose of cardioplegia was given, the heart and ascending aorta were de-aired, and the aortic cross-clamp was removed. When the patient's heart had adequately recovered and thoroughly de-aired, he was easily weaned from cardiopulmonary bypass. All cannulas were removed and the heparin effect was reversed with protamine. Hemostasis was obtained. Chest drains and pacing wires were placed, and the wounds were closed in standard fashion.

\section{Comments}

The effectiveness of coronary surgery is directly related to bypass graft patency. Arterial grafts have better patency than vein grafts (1). Therefore, to maximize the benefit of coronary surgery, many have advocated the use of multiple arterial grafts and limiting SV graft usage. Choice of arterial conduits include left and right ITAs, radial arteries, gastroepiploic arteries and inferior epigastric artery.

In situ left ITA to LAD grafting is the gold standard of surgical coronary revascularization. The right ITA, however, can be used in different ways. First, it can be used as an in-situ graft. However, in this configuration a lot of right ITA is wasted as a great length of the graft is utilized just to reach the coronary target. Second, the right ITA can be used as a free graft off the aorta. However, we know that the patency of this kind of graft is lower than the patency of in situ ITA graft (2), most likely due to the difficulty of constructing the proximal anastomosis to the aorta. An alternative is to put right ITA to the hood of the vein graft as that part of the vein graft is often open even if the graft is occluded. Third, and what we believe is the best approach, is to use the right ITA as $\mathrm{Y}$ or T composite graft off the left ITA. This doesn't waste graft length and at the same time we can do multiple bypasses with just two arterial grafts.

A concern regarding the use of ITA grafts is the effect of competitive flow (3). We know that greater competitive flow is associated with lower ITA graft patency. However, studies have shown that the decrease in ITA patency associated with increasing competitive flow is gradual and at no degree of proximal stenosis is there an acute decline in graft patency (3). Moreover, for the left coronary system, the patency of ITA grafts is better than the patency of SV grafts across all degrees of proximal stenosis. However, for RCA, the patency of SV grafts is better than the patency of ITA grafts for lesser degrees of proximal stenosis. Therefore, ITA grafts should be used to graft RCA only if it is critically stenosed (>90\% stenosis) or occluded.

We recommend that sequential and Y-grafting should be considered to maximize the use of ITA grafts in patients undergoing coronary surgery. A recent study has shown that sequential or Y-configuration does not compromise the patency of the ITA graft going to the LAD, and all segments of ITA used in sequential or Y-configuration have long-term patency similar to in situ LITA-to-LAD grafts, except for Y-segments which have slightly lower patency (4). However, Y-segment patency is still better than SV grafts.

Another concern regarding use of ITA grafts as composite Y-grafts is whether there is enough blood flow in different limbs of this configuration. Glineur et al. (5) studied the hemodynamic characteristics of 17 composite $\mathrm{Y}$-grafts made with the left ITA anastomosed to the LAD and with either the free right ITA or a SV graft implanted proximally to the left ITA and distally to the circumflex territory. They found that the Y-configuration allows an adequate revascularization of the whole left coronary system with an even distribution of perfusion pressure in both distal branches and a minimal resistance to maximal blood flow.

Radial artery grafts and GEA too are affected by competitive flow but probably to a much greater degree 
than ITAs. However, if we have highly stenotic vessels we can have excellent patency with these arterial grafts as well. Evidence suggests that radial artery patency can equal that of an ITA when it is grafted to a left sided vessel with high grade stenosis (6). GEA too have been shown to have excellent patency when used to graft coronaries with high grade stenosis. However, if a radial artery or GEA is being used to graft a RCA, it is important to make sure that the RCA is either critically stenosed or occluded, because the effect of competitive flow is more pronounced in the right coronary system than the left.

It is important to note that to maximize the benefit of coronary surgery, the choice of grafts and their configuration should be tailored to the patient's coronary anatomy as tailoring the operation to the patient is always best!

\section{Acknowledgements}

None.

\section{Footnote}

Conflicts of Interest: The authors have no conflicts of interest to declare.

Cite this article as: Raza S, Deo SV, Sabik JF 3rd. Onpump total arterial revascularization. Ann Cardiothorac Surg 2018;7(4):561-563. doi: 10.21037/acs.2018.06.06

\section{References}

1. Raza S, Blackstone EH, Houghtaling PL, et al. Influence of Diabetes on Long-Term Coronary Artery Bypass Graft Patency. J Am Coll Cardiol 2017;70:515-24.

2. Dion R, Etienne PY, Verhelst R, et al. Bilateral mammary grafting. Clinical, functional and angiographic assessment in 400 consecutive patients. Eur J Cardiothorac Surg 1993;7:287-93; discussion 294.

3. Sabik JF 3rd, Lytle BW, Blackstone EH, et al. Does competitive flow reduce internal thoracic artery graft patency? Ann Thorac Surg 2003;76:1490-6; discussion 1497.

4. Raza, S, Blackstone EH, Bakaeen F, et al. Long-Term Patency of Individual Segments of Different Internal Thoracic Artery Graft Configurations. Presented at 54th Annual Meeting of Society of Thoracic Surgeons 2018, Fort Lauderdale, Florida, January 27-31, 2018.

5. Glineur D, Boodhwani M, Poncelet A, et al. Comparison of fractional flow reserve of composite $\mathrm{Y}$-grafts with saphenous vein or right internal thoracic arteries. J Thorac Cardiovasc Surg 2010;140:639-45.

6. Maniar HS, Sundt TM, Barner HB, et al. Effect of target stenosis and location on radial artery graft patency. J Thorac Cardiovasc Surg 2002;123:45-52. 